\title{
On Integration of Computer Application Technology and Information Management
}

\author{
Guihua Xi \\ Computer Engineering College, Jingchu University of Technology, Jingmen Hubei, 448000, China
}

Keywords: Computer application technology, Information management, Integration.

\begin{abstract}
China is in the era of rapid development of information technology, and to promote the industry service and management, it is necessary to organically integrate computer application technology and information management together, thus highlighting the importance of computer technology, especially maximizing economic interests. Therefore, this paper explores integration of computer application technology and information management, and deeply analyzes any use of computer technology for the actual operation carried out during the process of information management, so as to provide reference for the application of computer technology in information management.
\end{abstract}

\section{Introduction}

At present, China has entered the era of big data, and effective management of information is particularly important to provide a favorable basis for promotion of the development of the industry. With increasing levels of computer technology, computer technology also has been widely promoted and applied in all walks of life, which is of great significance to enhance work efficiency and quality. In many industries, information management is required, then, it can be seen that information management plays a certain role in the development of the industry. In order to improve the efficiency and quality of information management, application of computer technology in information management is a necessity. In many areas in our country, computer technology is introduced into information management, in order to provide a favorable protection for carrying out information retrieval and information management work ${ }^{[1]}$.

\section{Connotation of Computer Technology}

With times changing, computer technology has also been significantly improved. Under normal circumstances, in the field of computer, application of computer technology and technical methods in the field is important for the development of the industry. There are a variety of computer technologies, including computer device technology, computer component technology and computer system technology and computer assembly technology. For computer system technology, computer is taken as a complete system, then with the aid of system management technology, system architecture technology and system application technology, computer system technology becomes more sophisticated. Under normal circumstances, application of system architecture technology can make the work carried out with high efficiency through the use of a computer ${ }^{[2]}$. With the gradual upgrading of the quality and performance of electronic devices, and significant improvement of solid engineering technology and micro-program technology, programming language and memory technology have also been improved. Computer software, hardware and other firmware are closely linked, which is important for improving computer architecture technology.

With the rising level of computer technology, computer database is more systematic, which creates favorable conditions for the development of system management technology. Application of computer system management technology makes information management develop towards automation and systematization, and scientific utilization of computer hardware and software resources provides favorable protection for operating system performance enhancement. By operating 
the computer, and then by means of a computer system, related personnel conducts effective management on resources, to realize man-machine communication management. In short, the rising level of computer technology plays an important role for the development of the industry. Extensive application of computer technology realizes automation management of relevant content, and can help to improve management quality and efficiency.

Computer technology has obvious comprehensive feature, therefore, computer technology is closely linked to mechanical engineering, electronic engineering, business management and many other aspects. Take communication technology and electronic computer technology as the foundation, with the continuous development of microelectronics technology, make computer technology significantly improved. At present, computer technology has been widely used in various industries, and given full play to its role, which is of great significance for the industry development.

\section{Advantages of Application of Computer Technology in Information Management}

Since entering the $21^{\text {st }}$ century, especially our country has a more profound understanding on science and technology, science and technology has also been significantly improved. Computer technology is one of science and technology, and its application in the actual production and life provides favorable conditions for speeding up socialist modernization and convenience of production and life. Currently, in the era of information technology and Internet, the rapid development of information technology provides opportunities and challenges for the industry development. In the era of rapid development, various work carried out requires quality assurance, and also efficiency, so the specific application of computer technology is important to accelerate the industry development. For either medical industry, or education and enterprise management, information management is inseparable, because information is the main basis for the effective development of all walks of life, and related information management by various departments can lay a good basis for the future work and other work. However, faced with complex and large amount of data, staff is prone to feel at loss, which has a serious impact on orderly information management. For example, the hospital manages medical record of patients and drug information, and the school manages students' information, etc. For such a large amount of data, traditional management tools result in lower management quality and efficiency, and thus cannot fully play the role of information management, and decrease the quality of information management ${ }^{[3]}$. Therefore, fully playing the role of computer technology, and introducing computer into education, health care and other industries, can minimize errors in information management, and facilitate information management to be conducted orderly.

Nowadays, with the growing popularity of computer technology, in information management, integration of computer technology and information management together organically, through information management, can play the role of computer technology. For example, when the school manages the library, since there are a wide range of books and a large amount of information regarding books borrowed by students, therefore, in order to improve the efficiency of information management, more and more schools introduce computer technology, and well integrate library information management and computer technology. Application of computer technology in library management can help staff quickly find and retrieve books. Only with the help of a computer and library management software, can staff use the mouse to quickly find books students need, therefore, the management efficiency gets improved. At the same time, it also lays a good basis for enhancing the quality of information management.

\section{Importance of Application of Computer Technology in Information Management}

Development of the industry promotes upgrading of economic level. In various fields, the number of information data shows an upward trend, and information data plays an important role in the industry development, then, information management is particularly necessary. Therefore, in the information age, information management has a pivotal role in the industry development. In the social

environment of computer getting popularized, application of computer technology in information 
management is significant to reduce corporate human resource, because it does not require many personnel during information management due to integration of computer technology and information management. In addition, with the aid of computer technology, limitations of manual operation can be efficiently improved, to prevent errors in manual operation, and the efficiency of information management achieves improvement to the greatest degree. Since information management is a complex and systematic project, and related work requirement is relatively high, if there exist any problem during information management, information management work quality will be severely affected. Therefore, in order to further improve the quality of information management, integration of information management and computer technology together is important to promote the quality of information management. In the big trend of social development, in order to make industry development meet social requirements, it is required to reinforce the importance of information management, and then take effective measures to manage the information ${ }^{[4]}$. Therefore, in the development process, in order to promote the sustainable development of the industry, and improve operational efficiency of enterprises, all industries should be sufficiently aware of computer technology and well integrate computer technology and information management, thus, with the aid of computer technology, maximize information management level and quality. Highly efficiently managed information can provide a favorable basis for the industry development and further promotion of the industry process.

\section{Measures of Integration of Computer Application Technology and Information Management}

\section{Build a perfect information management system.}

With the rising level of computer technology, computer technology has been widely used in various industries, which has played a crucial role in promotion of the industry development. At present, the importance of information management shows a gradually increasing trend, and information has a certain significance to accelerate the further development of the industry, so in order to promote sustainable development, all industries must attach great importance to information management, and take effective measures to enhance the effective management of information, so as to enhance the quality of information management, and provide a favorable basis for the comprehensive development of the industry.

The rapid increasing level of information technology lays a good foundation for the development of computer technology. Computer technology has its characteristics and importance, so in information management work, integration of computer technology and information management together organically creates favorable conditions for orderly information management work. Therefore, in order to integrate computer technology and information management science together, we must give full play to the role of computer technology, build a perfect information management system, and realize efficient management of information by the use of computer technology.

At present, China is in the information age, and in any industry and field, there will be information management, and corresponding information management staff, to carry out information management. During implementation of the information management in various enterprises, universities and hospitals, in order to improve the quality of information management, they must innovate management methods and means, to promote the quality and efficiency of information management. With the aid of computer technology, to early build a perfect information management system, other relevant enterprises and institutions must ensure that information management staff master computer technology and computer operation so as to lay a solid foundation to enhance information management quality and to some degree maximize the quality and efficiency of information management and play an important role ${ }^{[5]}$. Due to increased application of computer technology to provide good service for information management, so in the process of improving information management system, information management system needs to be more professional, they should make full use of network technology, database technology and multimedia technology to mutually integrate the above technologies and apply them into improvement of information 
management system. Enterprises, universities and hospitals should appoint professional personnel to improve information management system, through making full use of computer technology, then to integrate computer technology and information management together organically, so as to perfect information management system to enhance the security and stability of the system, laying a good foundation for the effective implementation of information management.

\section{Scientific management of inventory information.}

When integrating computer technology and information management, in order to improve the quality of information management, we should scientifically manage inventory information for reasonable application of computer technology in information management. In the information management process, in order to play the role of information in the industry development, we should ensure the information inventory, and information management staff regularly updates inventory information, and inventory information meets the actual demand. Meanwhile, clear away existing false information to improve the quality of information management.

\section{Improve information quality.}

Application of computer technology in information management creates favorable conditions to enhance quality and efficiency of information management. In the application of computer technology in information management, when computer technology and information management are integrated together, since there will be similar or the same information, and the presence of information duplication has a negative impact on the orderly information management work, reducing the quality of information management, and even leading to serious economic losses. Therefore, in order to effectively integrate together computer technology and information management, improve the quality of information, to provide a favorable protection for integration of computer technology and information management. When carrying out related work, personnel must gather complete information, classify and organize information, then carefully input the information into the database system, effectively store the information and data, and construct a more complete data system. For example, when colleges and universities manage information, during the integration of computer technology and information management, they must improve the quality of information, and information management personnel in accordance with the relevant standards and norms, apply computer technology to enhance the quality of information to the greatest extent so as to achieve integration of computer technology and information management science, which plays an important role in the development of the industry .

\section{Conclusions}

The rising level of science and technology provides a favorable environment protection for the development of all walks of life, and accelerate China's economic growth. Application of computer technology speeds up the process of the industry, and to some extent changes people's lives and production methods, which has important significance in practical application and promotion. At the same time, it increases the value of information resources. Therefore, the penetration of computer technology in information management plays an invaluable role in accelerating the development of the industry. However, how computer technology and information management integrate together organically is what people are widely concerned about. In order to give full play to the role of computer technology in information management, it is required to reasonably integrate and analyze these two factors, so as to achieve efficient information management.

\section{References}

[1] Ma Liyan, Cui Lin. On Integration of Computer Application Technology and Information Management, Henan Science and Technology, 2014 (8): 8.

[2] Liu Shuiwen. Integration of Computer Application Technology and Information Management, Computer CD Software and Applications, 2013 (18): 95-95, 97. 
[3] Zou Dajiang. Integration of Computer Application Technology and Information Management, Information and Computer, 2015 (21): 161-162.

[4] Ma Lan. Analysis on Integration of Computer Application Technology and Information Management , Information and Communication, 2015 (10): 151-152.

[5] Ai Yun. Integration of Computer Application Technology and Information Management, Wireless Internet Technology, 2014 (10): 189-189. 